\title{
Virtual Action Research for Virtual Organisations?
}

\author{
Frank Stowell ${ }^{1} \cdot$ Shavindrie Cooray $^{2}$
}

Published online: 1 June 2016

(C) The Author(s) 2016. This article is published with open access at Springerlink.com

\begin{abstract}
Business organisations have always existed in a constantly changing environment. To survive it is necessary for them to adapt and adjust to the changes. When analysing complex entities, such as organisations, researchers have frequently adopted the methods of action research. But with the advent of greater use of information and communication technology businesses are changing in their composition and one practical manifestation of this is the rise of virtual teams. Virtual teams reflect the trend for an organisation to comprise 'satellites' or clusters of expertise in different parts of the globe. Such a transformation of what we can now take as an organisation creates new challenges for managers and for those inquiring into organisational problems. In this paper we attempt to address the question whether action research is any longer a valid way of organisational intervention for the researcher and consultant alike. In this paper we describe field research in which a soft method of Action Research was used during the analysis phase of IS development as a means of understanding the problem domain, identifying information requirements, evaluating technologies and reducing conflicts. The research was conducted between two institutions that were separated by several thousand miles and all participants connected from individual locations using virtual synchronous ICT. The study provided insight into the use of AR in virtual settings and as a means of conflict resolution in virtual teams. The findings have implications for IS development (which is increasingly conducted in virtual teams), education and management among others.
\end{abstract}

Keywords Action research · Conflicts · Information systems · AIM · Organisational inquiry $\cdot$ Systems

Frank Stowell

frank.stowell@port.ac.uk

Shavindrie Cooray

scooray0512@curry.edu

1 School of Computing, Faculty of Technology, University of Portsmouth, Lion Gate, Portsmouth PO13AE, UK

2 School of Business Management, Curry College, 1071 Blue Hill Avenue, Milton, MA 02186, USA 


\section{Introduction}

Action research is widely accepted as a research method that makes research more relevant to practice (Zmud 1998) because of its focus on solving current practical problems while expanding knowledge. Although AR is increasing in popularity, as evidenced by the special issues dedicated to AR in leading IS journals (e.g. MIS Quarterly, Information Technology and People), the majority of the reported AR studies are conducted in traditional (i.e. face-to-face) settings. New developments in technologies (e.g. ICTs), organizations (e.g. globalization) and ISD (e.g. outsourcing, distributed virtual teams, open source software) have resulted in modern organizations that are globally dispersed where its members rarely meet (Corbett 2004; Gonzales et al. 2004; Deloitte 2014). The continued changes pushed by these developments means that many of the ideas popular in the AR and IS literature now face new challenges. The feasibility of using AR within this changing 'virtual' environment is unknown because of the dearth of AR studies carried out through virtual communication.

Investigating the practicality of $\mathrm{AR}$ in virtual settings is timely because recent research shows the way individuals act as part of a virtual group is different from their behaviour in face-to-face meetings (Sarkar and Valacich 2010; Sassenberg et al. 2005; Montoya-Weiss et al. 2001). Researchers have discovered that conflicts are more prevalent within virtual teams than with face-to-face teams. Sarker and Valacich (2010) argue that participants are more likely to change their initial points of view (shaped by personal values, biases and experience) and accommodate others views when discussions are held in a face-to-face environment rather than virtually. This finding raises doubts on whether AR when conducted virtually would reap the same benefits and outcomes as face-to-face AR. The problem is compounded since members of virtual teams may not share the same language nor culture but yet are an essential part of the enterprise.

The question we address is will the ideas on AR based upon the belief of getting 'out there' and gaining understanding from within, still work in the new virtual environment? We also investigate if those ideas (e.g. soft AR) can address one of the more documented problems associated with virtual teams- the issue of increased conflict. Our aim is to show the potential of AR within virtual synchronous teams by examining its use as a more participatory, user driven way of analyzing a problem domain and addressing issues of conflict.

We explore these questions within a synchronous virtual team comprising of members from two higher education institutions in the United States and United Kingdom. The team was tasked with identifying an action plan or business processes that would need to be in place to set up and sustain a study abroad partnership between the two institutions (within 1 year). The team was also expected to provide suggestions on information requirements and technologies for an IS that would support the endeavor. Due to the nature of our field research the results are especially relevant to IS development in virtual teams. We begin with an analysis of the relevant literature on the relationships between AR, conflicts and IS. We then discuss recent research on conflicts in virtual teams and their implications. A presentation of the virtual AR field research from its setting up and authentication to the different cycles follows. Finally, we evaluate the contribution of the paper in relation to the feasibility of virtual AR in ISD and use of AR for conflict resolution in virtual teams. 


\section{Action Research, Conflicts and Information Systems}

The roots of the AR movement can be traced back to Kurt Lewin's early work in the United States. Lewin (1948) set the stage for modern AR by demonstrating through his studies (e.g. use of tripe as part of daily diet in American families in WWII) that researchers could produce knowledge by solving real world problems (Greenwood and Levin 2006). This was in contrast to the longstanding tradition in the social sciences to assume that what is relevant and touched by the real world cannot be by definition the source of rigorous knowledge (Argyris et al. 1985). Lewin changed the role of a researcher from that of an objective observer to a participant in the problem domain. The roles of clients also evolved into those of co-researchers who together with the researcher build action plans, take action, reflect on the actions taken and make adjustments to the original theory based on learnings (Susman and Evered 1978). The Tavistock institute of Human Relations in London brought Lewin's work to the United Kingdom. The resulting study done in the English coal mines by Trist and Bamforth (1951) became the cornerstone of socio-technical systems theory and showed that the attainment of optimum conditions in any one dimension does not necessarily result in a set of conditions optimum for the system as a whole. This conclusion is classically Lewinian in its "emphasis on the total situation" (Reason and Bradbury 2013). The work of the Tavistock researchers was taken up by Norwegian researchers (e.g. Emery and Thorsrud 1976; Gustavsen 1983). This body of work convinced the Norwegian Confederation of Employers and the Trade Union Council to conduct a set of studies in various companies engaged in different types of production. These studies enhanced socio technical theory by showing a clear relationship between technology and work organizations. The early work by Lewin and those inspired by his work lead to AR being refined as a practical approach to theory development in that the knowledge produced was tested and refined within a real world problem domain. Subsequently AR is widely accepted as a research method that makes research more relevant to practice (Zmud 1998).

In general the cycle of AR begins with the diagnostic stage where the researcher and subjects of the research collaborate on analysing the situation at hand. This analysis results in the formation of theories about the nature of the research domain. The researcher and subjects then take action to test out the theories in the problem domain and later reflect on the results of these changes. Based on what was learned from that cycle new theories are formed and tested out in subsequent iterations (Blum 1955).

Many variations of action research have emerged over the years, although all mainly adhere to the basic tenets of Lewin's notion of AR. But some differ in the underlying epistemology, and as a consequence so too do the 'tools' used. For example, there are differences in the level of participation e.g. a series of individuals or group participation; the motivation of the researcher e.g. learning about the method or using it as a means to an end; the situation of interest-its context. This latter point is important in this paper as we apply AR in a virtual team environment to enable us to test out the ideas we have used previously in a conventional organization and report about the way they worked in this situation; the relationship between theory and practice in this new environment.

Action Science (Argyris et al. 1985; Argyris and Schön 1996, p. 223) is one such approach that argues for a link between theory building and theory testing. Action science uses a concept called 'confronting' to force participants to analyse their own defensive reactions to perceived threats by inquiring into the causes of those reactions. While the analysis of motivation of participants is welcomed we have resonance with (Greenwood 
and Levin 2006) in that the focus on defensiveness is not plausible, since it is not the only major psychological process relevant to groups. The method of action science also considers conflicts as opportunities for generating new knowledge and use the concept of frames to reach an agreement (Friedman and Rogers 2013). The concept of a frame stems from the assumption that humans construct images of reality from the raw materials of sense perception. Frames reflect the tacit choices people make and influence the way they perceive reality. We argue that frames are similar to what Vickers called "Appreciative settings", which are the values, biases, experiences and standards that influence the way humans select ideas that are relevant at a given time. Action science researchers argue that in conflictual situations an agreement can be reached by participants jointly uncovering and testing their frames using tools such as "personal cases" and the "ladder of inference". While these ideas show promise to our knowledge there are no examples in the literature of action science studies conducted in virtual synchronous environments.

Cooperative Inquiry, collaborative inquiry and action inquiry are a group of AR approaches that are interrelated through the work conducted at the University of Bath led by Peter Reason (Reason and Rowan 1981; Reason and Bradbury 2013). Reason and Bradbury (2013) argue that Cooperative inquiry is research "with" instead of "on" people by suggesting that all participants should be involved as co-researchers in the research process. Cooperative inquiry calls for the distinction between first person, second person and third person research and practice. These ideas have implications for group dynamics and conflict resolution in teams. First person inquiry is introspective in nature and focusses on the researcher learning about her own actions and states of awareness (Greenwood and Levin 2006). Second person research and practice involves the disciplines of dialogue and listening with and in the context of others (Torbert 2001). Activities central to second person research and practice include "... attempts to "frame" the discussions and have that framing open to response from other participants, to advocate or assert positions in a dialogical context where they can be analysed and responded to, to offer illustrations to back up assertions and then to inquire of the others in the situation about their reactions" (Greenwood and Levin 2006). Cooperative inquiry is similar to action science in that personal "frames" of participants are exposed as a way to both reflect on one's own motivations and as a means of explaining one's assertions. The implication is that such a process can lead to more agreement between participants in conflicts. To our knowledge there are no examples in the literature of cooperative inquiry studies conducted in virtual synchronous environments.

Critical Participatory AR (Kemmis 2013) suggests that interpretation is a process of interpreting ourselves as well as the object we are trying on interpret (Habermas 1972) which has some similarities with other forms of AR. Critical PAR differs from other forms of AR in its call for participants to be "critical" in "trying to find how particular social structures and practices conspire to produce untoward effects" (Kemmis 2013). Critical PAR acts negatively against irrationality and injustice rather than positively for a view of shared understanding and conflict resolution (that approaches such as Action Science, Cooperative Inquiry and Systems thinking advocate).

Unlike Agile methods (Paetsch et al. 2003; Ashrafi and Ashrafi 2008), which focus on a more component based view of a problem domain, AR focusses on a more holistic or systemic view of the situation of interest. Systems thinking has influenced several approaches to AR such as soft systems (and its relationship to phenomenology and interpretivism), systems dynamics (emphasising patterns of influence) and critical systems approaches (focusing on critical theory). In contemporary systems thinking a system is considered to be a process or a way of thinking about the interconnected elements that 
make up a "whole". Systemic thinkers pay particular attention to interconnections while systematic thinkers follow a recipe in a step by step manner (Ison 2013). Systems thinkers argue that each person's system of interest in the same situation will be different based on their personal boundary judgments that are influenced by his/her experiences, values, biases etc. Boundary judgements helps each individual select his system of interest from the environment. These ideas share similarities with Vickers "appreciative settings", Gadamer's "horizons" and the notion of "personal frames" (Friedman and Rogers 2013).

Despite repeated calls in the literature for increased systems thinking in IS research (Alter 2013; Baskerville and Wood-Harper 1996) there are still limited examples of its use in IS development. The notable instances of the use of systems thinking AR methods in IS development include soft systems inspired methods (Checkland and Poulter 2006; Checkland and Holwell 1998; Champion and Stowell 2005; Mathiassen et al. 1991; West 1995; Cooray 2010; Hart 2013), critical systems inspired methods (Avison and WoodHarper 1990), mixed methods based systemic approaches (Multimethodology, Mingers and Brocklesby 1997; Chiasson et al. 2009) and Socio Technical approaches (ETHICS Mumford and Weir 1979).

The soft systems based methods of AR are inspired by the 30 year old AR program at the University of Lancaster which drew considerable IS attention to AR (Baskerville and Wood-Harper 1996; Baskerville 1999). In this paper we refer to soft systems inspired methods of AR as "soft" AR. The Action Research programme at the University of Lancaster is influenced by the phenomenology of Husserl (2002) the sociology of Schutz (1970) and the hermeneutics of Gadamer (1998). The emergent methods from this programme by the work of Churchman (1971) on Inquiring Systems, Checkland (1999) Soft Systems and Vickers (1983) notion of the Appreciative System. This version of AR subscribes to the notion that an objective view of a situation does not exist. It allows for differing views of the research domain to emerge during the course of discussions. These debates lead to learning, or as Gadamer calls it a "fusion of horizons" (Gadamer 1998) where multiple views converge to portray the "big picture" or holistic view of the problem situation.

The action researchers from Lancaster have demonstrated that accommodations can be reached in conflictual situations by enabling clients to learn about the situation of interest as a "whole" and exposing multiple perspectives of the situation. This version of $A R$ calls for a thorough systemic analysis of the problem domain before considering the actions that could improve the situation. Research has demonstrated that systemic learning can lead to the identification of the actual 'problem' (which sometimes differs from the original perception) and helps define the business processes that will improve the situation. Researchers (Checkland and Holwell 1998; Champion and Stowell 2005; Cooray 2010) have shown that an information model for the domain can be produced by considering the information that would be needed to fulfil the identified business processes. The main theme behind the Lancaster model of AR is that the "system to be served" (business processes that client should do to improve the situation) needs to be identified before considering the "serving system" (the tools or technology that will help clients do the identified processes). By focusing on the "system to be served" soft AR engenders a process that results in an IS solution that is better aligned with the goals of clients. Soft action researchers also resist from making the assumption that clients already know their problem and needs. Instead clients and researchers embark on iterative cycles of action and reflection which results in a better understanding of the different aspects of the domain of research. Once clients learn about their situation then they are better equipped to identify the actual problem and requirements (Checkland and Holwell 1998; Stowell and Welch 
2012). This is in contrast to popular ISD methods (e.g. agile, RAD and waterfall), which assume that clients already know about all aspects of the situation and require clients to list out their needs at the initial stages of a project.

\section{IS Development in Virtual Teams}

Examples of AR studies in the IS discipline are widely conducted in the face to face setting studies (such as Lindgren et al. 2004 (Canonical AR), Champion and Stowell 2005 and Cooray 2010 (Soft AR) Iversen et al. 2004 (Collaborative practice research), and Mårtensson and Lee 2004 (dialogical AR)). But there is little evidence of its use in virtual environments, which is particularly troubling in light of the increasing number of IS projects conducted by globally dispersed teams. Agile methods, while being the most popular among virtual IS teams at present, do not offer the focus on client learning (leading to out-of-the-box solutions and the identification of the 'real problem'), emphasis on action for improvement versus technology and focus on holistic analysis that AR offers. These benefits become more valuable in light of recent research on virtual teams.

A virtual team can be described as consisting of members who are geographically dispersed and communicate using computer mediation communication (Kanawattachai and Yoo 2007). Members in a virtual team can synchronously talk to each other in real time using channels such as videoconferencing or communicate asynchronously by adding to the ongoing discussion at different times using channels such as email chains, discussion boards etc. Current research shows the way individuals act as part of a virtual group is different from their behaviour in face-to-face meetings (Sarker and Valacich 2010; Sassenberg et al. 2005; Montoya-Weiss et al. 2001). Researchers have discovered that conflicts are more prevalent within virtual teams than with face-to-face teams. Sarker and Valacich (2010) demonstrate that participants are more likely to change their initial points of view (shaped by personal values, biases and experience) and accommodate others views when discussions are held in a face-to-face environment rather than virtually. The problem is compounded since members of virtual teams may not share the same language nor culture but yet are an essential part of the enterprise. These findings have implications for ISD since the process relies on the effective transfer of domain knowledge from clients to developers (system to be served) and knowledge on the technologies from the developers to clients (serving system). Conflict between virtual IS team members can lead to a breakdown of communication and result in IS that are not well aligned with the needs of clients. These problems identified by researchers highlight the need for an alternative approach to virtual ISD that is more focused on learning, challenging initial points of view and creating shared understanding. It is to this end we (a) explore the applicability of AR as an approach to ISD in a virtual synchronous environment and (b) investigate the Lancaster version of AR (soft AR) as a means of ameliorating the problem of conflict, which research suggests is more prevalent in virtual teams.

\section{Field Research}

\section{Exploring the Implications of the Research Questions}

In order to explore these research questions it was necessary to work on a real problem with a real organization. In March, 2013 the Chief Academic Officer (CAO) of Curry College (CC), Boston, USA requested that contact with a potential collaborator be established and an initial assessment of the feasibility of starting a study abroad partnership 
be explored. The charge was to explore what business processes would have to be in place to initiate and maintain a study abroad partnership. A description of the information requirements for these processes was also to be provided. Suggestions on how technologies could help acquire, store, process and distribute that information was also welcomed. Based on the initial requirements of the institutions it was understood that the study was expected to cover the analysis and information requirements definition stage of the Software Development Life Cycle (SDLC) in ISD while the implementation was to be left to the IT departments at the respective institutions.

The project was set up between Richmond University ${ }^{1}$ (RU) in the United Kingdom and Curry College (CC) USA. The Dean of International Programs at Richmond University and the Director of Admissions North America from Richmond University were brought together. The initial contact was made through a face-to-face meeting (May 21st 2013) followed by a series of e-mails.

Although the participants of the study were located in two continents it was important that the key stakeholders participated in the study. To this end a virtual communication environment was created. Initially an asynchronous communication environment (i.e. email) was used by participants, but it became apparent that they needed to meet 'virtually' at the same time to facilitate productive discussions. A synchronous virtual environment was created allowing participants to talk to each other and see each others video feeds in real time. This approach meant that there was a more equal participation among team members because of the higher levels of social presence, (the extent to which one becomes aware of others), created by the synchronous use of audio and video (e.g. Paulus and Phipps 2008; Pena-Shaef et al. 2001).

The free web based synchronous software tool 'Wiggio' was chosen as the communication technology because it provided, audio, video and texting capabilities for participants to communicate synchronously, which assisted in replicating a face to face environment as close as possible. Wiggio also provided a whiteboard feature that participants could use to create/edit a diagram together in real time.

All participants were located separately and joined the study from different locations across the USA and UK. None of the participants were in the same room during the study. The equipment used by each participant was as follows

Individual Laptops with microphones and headsets

Access to a connection to the internet

Wiggio, virtual meeting software delivered over the internet. Participants are not required to install software on their own computers.

The project brief given to us required that we be active participants but the choice of the method and its suitability to the task was left to us.

\section{Choosing a Methodology}

The dual goals of the study (research and practical) were aligned with AR, which allows for the generation of new knowledge along with useful practical outcomes for clients. The 'systems thinking' based view of a situation was ideal for the task at hand since it called for a thorough analysis of the problem domain before considering the actions that could improve the situation. The clients understood that they did not have a "big picture" view of the problem domain and that many "pieces of the puzzle" were yet unknown. Our charge was to identify an appropriate systems thinking based tool to conduct the analysis and

\footnotetext{
${ }^{1}$ Richmond, The American International University in London.
} 
requirements definition phase. Out of the available systemic approaches to ISD (Checkland and Holwell 1998; Avison and Wood-Harper 1990; Mingers and Brocklesby 1997; West 1995; Champion and Stowell 2005; Cooray 2010; Mumford and Weir 1979; Mathiassen et al. 1991) we selected the Appreciative Inquiry Method (AIM) since it appeared to be best suited to the context of the specific situation.

Although Soft Systems Methodology (Checkland and Holwell 1998) was most referred to in literature it was less suitable within our synchronous virtual setting since the stakeholders were not very technically proficient and drawing rich pictures on the computer (the preferred tool of choice in SSM) was unrealistic. We chose AIM since (1) the tool of choice is a simple Venn diagram, which can be easily drawn on the computer by participants (2) it is better suited for situations where all can agree in advance upon the question/issue to address (3) allows all participants to contribute to the development of the ideas relating to the issue/ question (4) provides tools that promote discussions and shared understanding.

AIM comprises three phases which are Appreciate, Articulate and Actuate. In these stages participants use systems maps (similar to Venn diagrams), PEArL (Champion and Stowell 2001; Cooray 2010) and activity models to expose multiple perspectives of the research question, create a shared "systemic" understanding of the issue and generate an action plan. A diagrammatic representation of AIM is provided below but for a full account (see Stowell 2014; Stowell and Welch 2012, pp. 51-57) (Fig. 1).

PEArL (Champion and Stowell 2001) is another systemic tool that is used frequently with AIM and has shown its usefulness in several different contexts. The mnemonic PEArL consists of five different elements (see Table 1).

Originally PEArL was conceptualized as a tool to record the manner or atmosphere within which participants interacted within an inquiry (Champion and Stowell 2001). The original intention was to help external parties authenticate a study and understand how results were reached even though they might be unable to replicate the results. Recently PEArL has been also applied in two other contexts. First it has been used by researchers (Cooray 2010) in an introspective manner to reflect on the way they interacted in the study and as means of identifying their motivations for the purpose of improving themselves. This shows similarities with first person research which demands that the

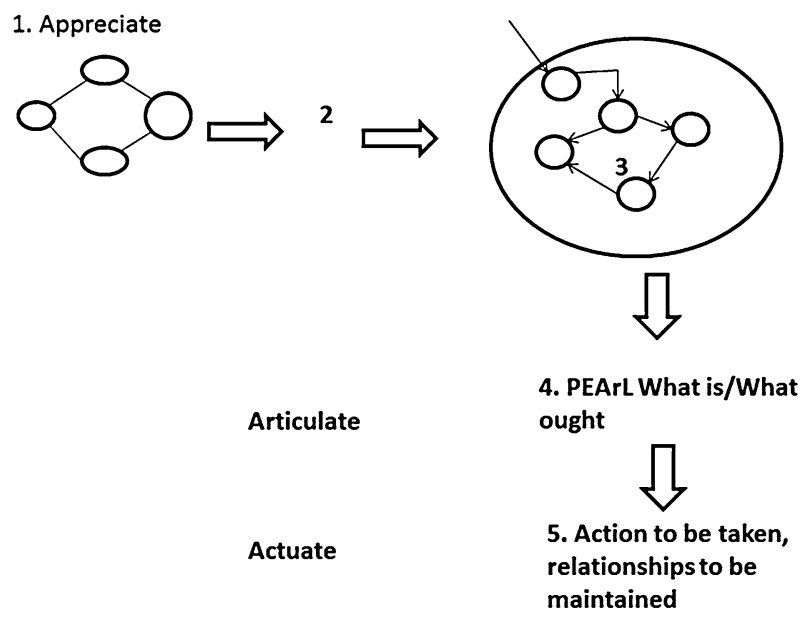

Fig. 1 Schematic Diagram of AIM 
Table 1 List of PEArL elements

\begin{tabular}{|c|c|}
\hline $\begin{array}{l}\text { Elements of } \\
\text { PEArL }\end{array}$ & Issues to reflect upon \\
\hline $\mathrm{P}$-Participants & $\begin{array}{l}\text { Who is Involved in the activity, who is excluded and why? Why are they involved? What } \\
\text { is their role in the activity? }\end{array}$ \\
\hline E-Engagement & $\begin{array}{l}\text { How are the participants involved? What methods are used to engage participants? What } \\
\text { are the environmental influences in which an activity takes place? }\end{array}$ \\
\hline A-Authority & $\begin{array}{l}\text { Formal authority associated with activity, What are the environmental influences? What } \\
\text { embedded authority do the tools for engagement have? Why were they chosen and } \\
\text { what influences the outcomes? }\end{array}$ \\
\hline $\mathrm{r}$-relationships & $\begin{array}{l}\text { What kind of informal power or commodities (Stowell 2014; Stowell and Welch 2012, } \\
\text { pp. 116-118) do people use to influence others (Examples include the use of gender, } \\
\text { sociability, and verbal skills) }\end{array}$ \\
\hline L_Learning & $\begin{array}{l}\text { The theoretical and practical outcomes from the activity, judgments about how these } \\
\text { were achieved and assessment about the ownership of outcomes }\end{array}$ \\
\hline
\end{tabular}

researcher learn about her own actions and states of awareness (Reason and Bradbury 2013; Greenwood and Levin 2006). Second it has been used as a sense making tool to enable participants to reflect on different aspects of an issue, process or domain in a more holistic manner (Cooray 2010; Stowell and Welch 2012). In this study we use PEArL in all three contexts.

PEArL has shown its flexibility as a sense making tool by being used as a means of analyzing issues arising from SSM investigations (Cooray 2010) and from AIM studies (Hart 2013). Researchers have found that the questions related to PEArL can be used as guidelines to learn about "what is the case at present" with regards to a problem domain or issue (corresponding to Vickers reality judgements) (Vickers 1983) and "what ought to be the case in an ideal setting" (corresponding to Vickers value judgements) (Vickers 1983). Studies have demonstrated that using PEArL in conjunction with Vickers ideas can lead to a better understanding of issues arising from AIM and SSM investigations. For a full account of PEArL as a sense making tool (see Cooray 2010; Stowell and Welch 2012).

\section{Authenticating the Research}

The underrepresentation of AR in organizational and IS research has been partly attributed in the literature to difficulties in validating AR. According to See Pui et al. (2010) the personal biases of the researcher can threaten the validity of qualitative action research which corresponds to arguments made by (Susman and Evered 1978; Checkland and Holwell 1998; Davidson 2002) that AR researchers are active participants in an inquiry, both influencing and being influenced by it. Researcher bias was minimized in the study by

- The researchers consciously striving to let the participants be in control of the process of inquiry

- Giving participants a chance to edit and confirm the study data, the researcher's interpretation of the study data and the conclusions reached; and

- Using the mnemonic PEArL (Champion and Stowell 2001) as a tool to record the manner in which the researcher participated in each session.

After each session in the study two types of PEArL records were created. The first was a PEArL record to document the researcher's interpretation of the manner or atmosphere in which the session took place (i.e. interactions between participants) so that an external 
party could understand how the results were reached (recoverability-Checkland 1999, p. A40) even though they may not be able to reproduce the exact same results (Champion and Stowell 2005; Cooray 2010) (see Table 2 for example). This type of record was created to address the challenge in qualitative social research of being unable to replicate social situations in exactly the same way due to the dynamic and unpredictable nature of people.

The second type of PEArL record (see Table 3) was a personal record of the researcher's reflections on her own interactions during each session. This type of record was used to assist both an external party and the researcher to trace how the researcher may have influenced the sessions. This type of record can be introspective in nature and the researcher can use this to reflect on her own role within the study. Both types of records can be used to reflect on how each session was conducted and used by external parties to interpret and authenticate the results of the study.

The maintenance of rigor is another challenge faced by AR researchers especially since it is difficult to replicate the results of social inquiries (in the way one can with science experiments) due to the dynamic and unpredictable nature of participants. Checkland and Holwell (1998) suggest the notion of 'recoverability' as a way of addressing the issue and argue that external parties should be allowed to see the intellectual thought process that led the inquirers to reach a conclusion even if they might not be able to reach the same conclusion themselves. Checkland (1981) argues that AR researchers should document the potential application area (A) framework (F) for understanding A, and a methodology (M) for problem solving within A based on $\mathrm{F}$ before the study takes place. This is to ensure that external parties can see the thought process that led to conclusions being reached and contributes to the rigor of AR.

Based on Iversen et al. (2004)'s interpretation of Checkland and Scholes (1999)'s action research cycle and FMA model this study combines theory and practice as follows.

- Research Framework (F)-AR, virtual teams in IS development

- Research Methodology (M)-AIM

- Real world problem situation (A)-The research focuses on identifying the potential of AR (specifically the Lancaster model of soft AR) in the analysis phase of ISD as a means of creating shared understanding and reducing conflicts in virtual teams.

Table 2 PEArL record to document the manner or atmosphere in which the session took place (for the meeting with representatives from RU)

PEArL Observations

elements

Participants Representatives from Richmond University, Researcher

Engagement Participants seemed very comfortable with the use of Wiggio especially since they had attended the test session previously where the researcher demonstrated how Wiggio could be used. Most participants made changes to the map themselves on whiteboard although at times the researcher was asked to add the elements they described. They debated points and frequently made changes to the map

Authority Participant X had highest rank

Relationships An atmosphere of cordiality prevailed. One participant did mention that he had spearheaded many study abroad partnerships in the past and frequently drew on his past experiences to articulate a point. This may have led to that participant being perceived as having more credibility and hence exercise informal power over the others

Lessons Learned more about the central question. Being able to see the map displayed on the whiteboard helped participants to think clearly. They also learnt about using synchronous virtual meeting software 
Table 3 PEArL Record to Reflect on researcher's involvement in the session with RU

\begin{tabular}{ll}
\hline $\begin{array}{l}\text { PEArL } \\
\text { elements }\end{array}$ & $\begin{array}{l}\text { Observations } \\
\text { Participants }\end{array}$ \\
Engagement & $\begin{array}{l}\text { Representatives from Richmond University, Researcher } \\
\text { The researcher explained the tasks to the participants and then only spoke when participants } \\
\text { wanted some clarification. Some of the participants were not comfortable editing the } \\
\text { whiteboard themselves and requested the researcher to add their ideas to the map. In the } \\
\text { situation the researcher immediately asked for feedback on what was added }\end{array}$ \\
& $\begin{array}{l}\text { Participants from Richmond had authority although the researcher had some authority as } \\
\text { the one most experienced with the Wiggio tool and AR }\end{array}$ \\
Authority & $\begin{array}{l}\text { An atmosphere of cordiality prevailed. The researcher was both the facilitator and a faculty } \\
\text { member of Curry College. In the study the researcher played the role of facilitator and } \\
\text { tried to ensure that she did not influence the proceedings. However in such a situation } \\
\text { where the facilitator also has a stake in the problem situation if proper care is not taken } \\
\text { the facilitator can possibly yield informal power using her extra knowledge in the method } \\
\text { of inquiry and technology used. The approach adopted by the researcher was to explain } \\
\text { what was required to participants and then only speak when participants had questions or } \\
\text { needed clarification } \\
\text { Learned that some participants knew much more about the study abroad program than } \\
\text { others. Made a note to figure out how to get the others more involved }\end{array}$ \\
Lessons &
\end{tabular}

\title{
Cycles of Learning for Action
}

\author{
Cycle One
}

As discussed previously the researcher met with the CAO of CC and the Dean of International Programs of RU in Boston in May 2013 to have the initial discussions. Since the researcher is a full time faculty member at $\mathrm{CC}$ she worked with the CAO to identify a list of potential participants from CC. The Dean of International Programs at RU worked with the Director of Admissions (North America) to identify a list of potential participants from RU. The researcher contacted the participants via email and explained the processes involved in the study. Once the list of participants was confirmed they were added to an email thread and asked to discuss and agree upon an initial question to explore. The question was agreed on through email discussions and is as follows.

"How can we make the exchange program between $\mathrm{CC}$ and RU more attractive to students so that a sustainable relationship between the institutions becomes feasible?"

Although participants were able to agree on a question it became apparent that they would need to be able to communicate in real time in order to have more productive discussions. Since participants were located in the US and UK it became important to explore the option of synchronous virtual meeting software. The free web based synchronous software tool 'Wiggio' was chosen as the communication technology because it provided, audio, video and texting capabilities for participants to communicate synchronously. Wiggio also provided a whiteboard feature that participants could use to create/edit a diagram together in real time. Prior to the group sessions the participants were given individual basic online training on Wiggio by the researcher. The training for the participants in both the UK and US was done via the internet with the exception of one face 
to face training done with a participant at CC. Participants were taught how to log into Wiggio, edit their sound and video settings so that they could hear, talk to and see others, to edit the whiteboard, to share documents and share their desktop. A brief overview of the goals of study and the process of AIM was also discussed. Once participants were confident that they could $\log$ in and participate from their individual locations two group sessions were set up- one for the participants from CC and another for those from RU. Each participant joined the sessions from different locations.

The first session was held with RU and the participants included one researcher, the Director of Admissions North America and two faculty members who were directly involved with the 'study abroad' partnership in the UK. The researcher was located in the US while the other participants were at different locations in the UK.

Each participant joined the session from his/her own laptop using the software Wiggio. Participants were able to see and hear other participants by using the audio and video features of Wiggio. The participants were asked to focus on the agreed central question. The whiteboard on Wiggio was opened and the central question added within the centre circle on the board. All participants could see this in real time. The participants were invited to add their own thoughts to the central question by adding circles to the centre in the Venn convention of a Systems Map.

The shared whiteboard meant that participants were able to modify the systems map in real time. One participant stated that he was not technologically experienced and requested that the researcher add his elements to the map. This was done in real time. The participants could see what was added and make amendments if necessary.

Participants from RU, collectively, produced the following systems map (Fig. 2).

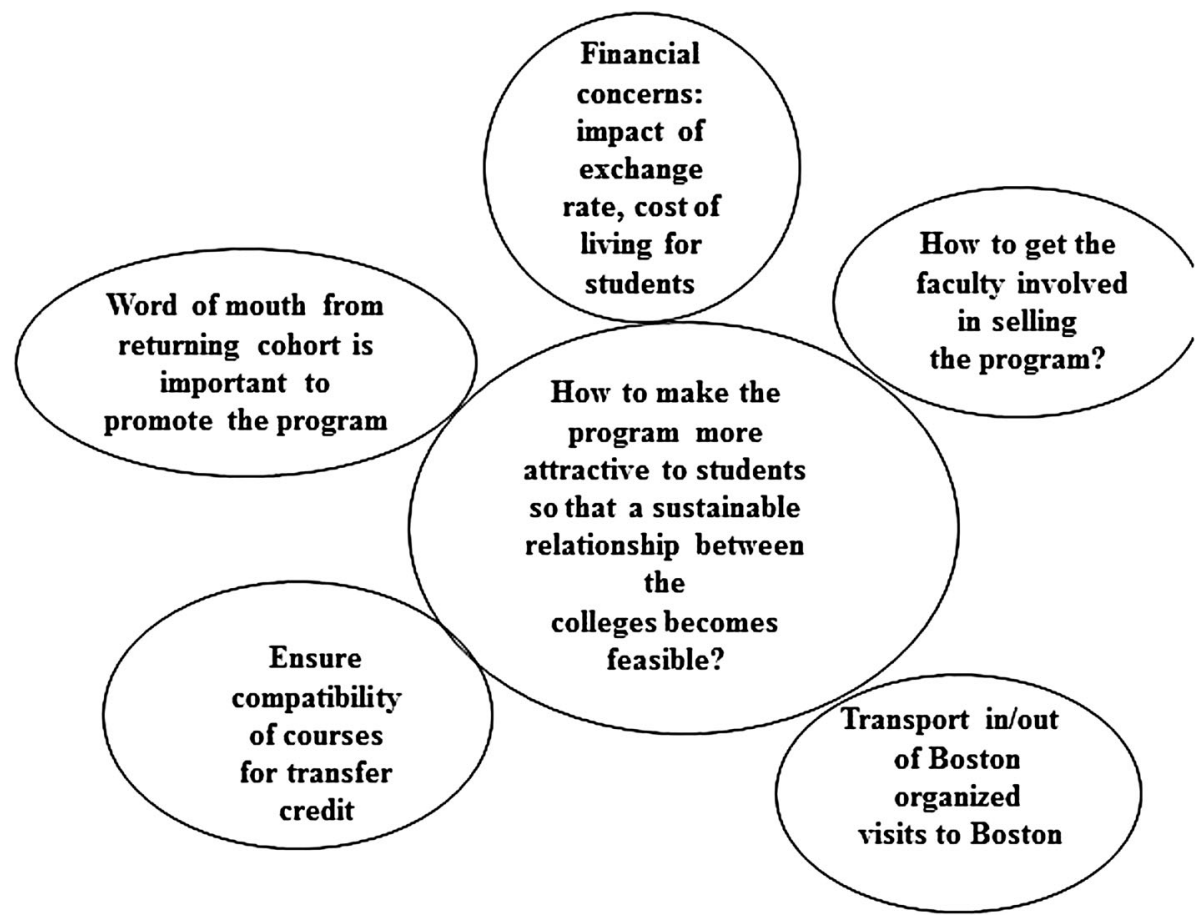

Fig. 2 Systems map produced by members of RU 
Participants then discussed and clarified any components of the map that they did not understand or disputed. Their comments were documented as a record of the process that had taken place. There was an atmosphere of general cordiality throughout the session although it did appear that certain members, who had past experience in study abroad programs, might have had influence over the others because of the way they chose to disclose this. This manifested through the informal comments about their past experience, which may have given them more credibility and power in the eyes of others (e.g. was this an example of informal power, ' $r$ ' in PEArL-Stowell 1989).

Participants asked questions when they did not understand an element in the systems map and those who had added the element explained their reason for doing so. This process sometimes generated a discussion. For instance, when participant $\mathrm{X}$ added that he would like to see the financial specifics of the study abroad program be more transparent participant $\mathrm{Y}$ did not agree with this proposal. After some discussion the participants decided to delete this element from the map altogether since participant $X$ accepted participant $Y$ 's explanation on why it would be legally difficult to do so. The depiction of the element in a visual manner on the 'white board' (in the systems map) made each idea more explicit and ensured that the discussion was more structured than rambling. The act of adding (or deleting) an idea drew attention to it encouraging the contributor to explain what s/he meant. One problem noted during this stage were the delays in the network meaning other participants had a wait for a few seconds. But once the delay was understood the 'Wiggio' environment proved to be successful as it allowed participants to discuss the map in real time. This session ended with participants from RU agreeing on their version of the systems map. In the second session participants from CC repeated a similar exercise. The participants from CC included the Director of Academic Enrichment, the registrar and a faculty member associated with the study abroad program. The systems map collectively produced by participants at CC in session two is as follows (Fig. 3).

It became apparent during cycle 1 that not all participants were fully supportive of the study abroad partnership and that there was an underlying tension. This manifested when one participant $(\mathrm{X})$ added the element "Make financial specifics more clear to faculty and staff who are organizing programme so everyone can get behind it". When the participant (who was an academic director) added this element the Director of Admissions North America (Y) immediately asked it be clarified adding all the available information had been passed on. During the ensuing discussion of the map the participant who had added the element said that he felt that his department was not given access to all the relevant information. Upon realizing that not everyone felt comfortable with the proposed partnership there was renewed interest among the senior management (Director of Admissions North America) to examine issues pertaining to the central question further since they believed that by doing so they could identify the underlying reasons for tensions. The participants decided that they would need to disseminate certain types of information among their staff (and each other) before the next sessions. They used the systems map as a means of identifying the types of information to be passed around. Although the "financial specifics" element was removed from the map it is noteworthy that participant Y stated at the end of session that he would try to email more financial information before the next meeting. The participants then dispersed to take the action they had identified.

After each session, two types of PEArL records were created. The first was to record the researcher's interpretation of the manner or atmosphere in which the session took place (i.e. interactions between participants) and the second was to document the researcher's own interactions during the session. These records can be used by external parties to help 


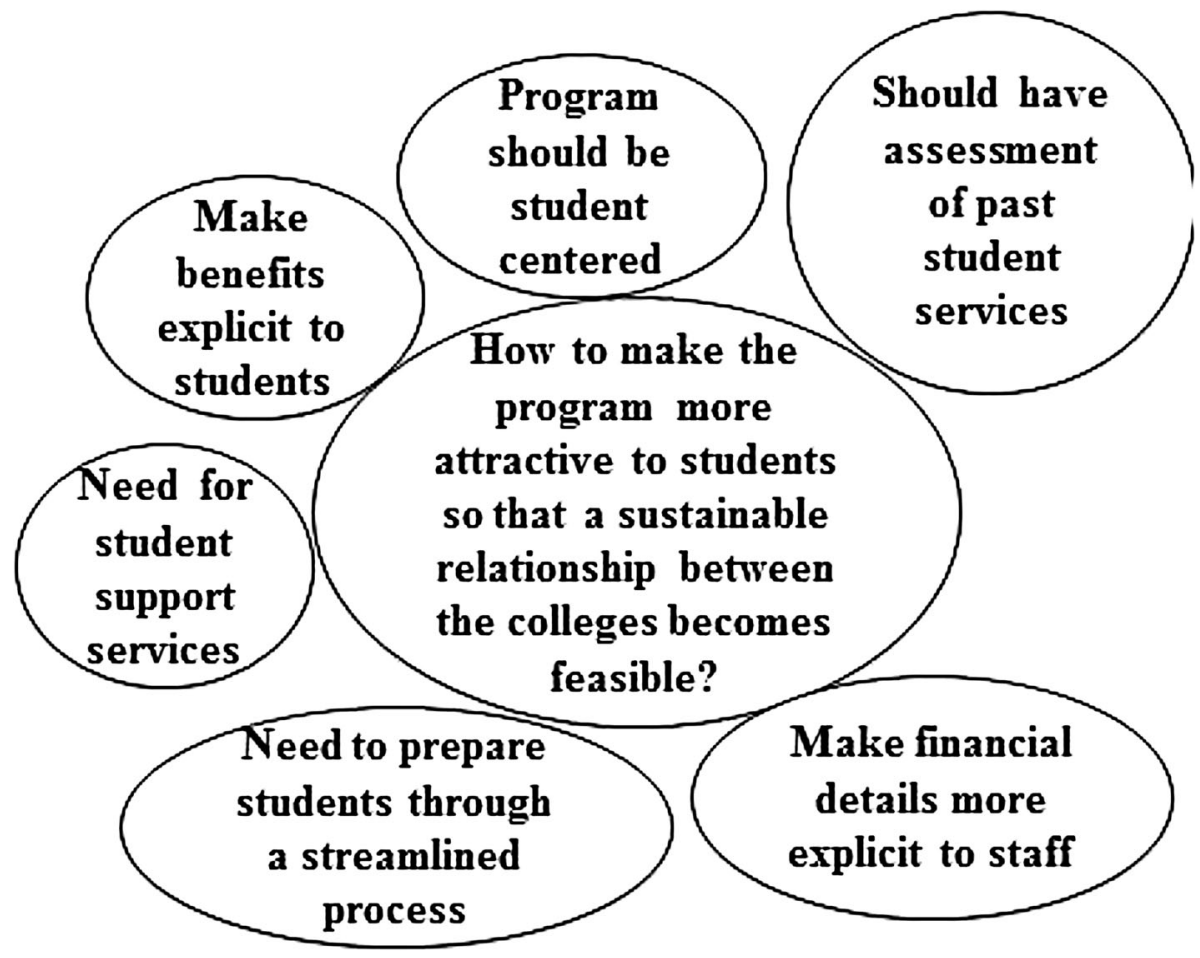

Fig. 3 Systems map produced by CC

them to understand how each session was conducted and to assess how much influence the researcher had over the process.

The participants used the elements in the systems maps and learning from the discussions in order to decide on what information to disseminate among staff. Each participant had staff who reported to them with direct involvement to the study abroad program. At $\mathrm{CC}$ the director of Academic Enrichment created a site on the Blackboard learning management system and gave "instructor" access to the other participants. They were then able to add any other staff members as "students" to the site. As a faculty member of CC the researcher was also added to the site. Over the next 2 of months' participants added new documents on the issues discussed during the session. A discussion board was also created on the site to promote asynchronous discussion on the shared documents. Unfortunately, there was very limited activity on the discussion board. At RU relevant material was shared via email.

Although relevant information was shared with participants the results of the actions could not be evaluated since there was limited activity on the Blackboard discussion board at CC. Similarly, email was only used to provide material and there was no way to assess feedback from the recipients of the information. The researcher was not privy to the information shared at RU. It became apparent that more real time virtual sessions would be required to (a) assess the results of the actions (b) generate an inter-group level view of the problem domain and (c) evaluate if the tensions from earlier was still visible after the action taken. 


\section{Cycle Two}

The purpose of cycle two was to assess the impact of the action taken in cycle one and explore the conflictual issues further using "soft" thinking tools. The intention was to arrive at a group level shared agreement on the problem domain by participants from both institutions. This would then be the starting point of an investigation into what business processes and information requirements would have to be in place to create an effective IS that could help to launch the new study abroad program.

Three sessions were held for cycle two with all the participants from cycle 1 (i.e. both institutions) at the same 'virtual' meetings. Participants were at different locations connected via their laptops using Wiggio. Prior to the first session the researcher combined the two maps produced during cycle one into one composite systems map. This was presented on Wiggio's whiteboard during cycle two to the group for comment. Participants reviewed the map, discussed any disputed elements and agreed changes to the map. They stated that their staff reacted positively to the dissemination of information after the previous cycle although they acknowledged that the information was, primarily, only communicated one way and that feedback was mostly on a one to one informal basis. Subsequently participants decided that more channels of communication should be opened for those outside the study (but directly reporting to the participants) to asynchronously discuss and share ideas. Participants decided that moderators should be appointed to these forums to ensure that the participation is high. They also wanted to open up the discussion to those outside of the study not directly involved with the study abroad program such as faculty in the different departments. The idea of organizing offline information sessions for faculty and staff was discussed as a means of getting feedback and buy in from faculty. Participants changed the elements in the map as a result of the reactions of their staff after the previous cycle. They also changed the elements in the map in response to the views of others present at the session. Participants analyzed each element in the map by asking the 'owner' of the element to explain their reasoning. Any disagreements were discussed and, sometimes, the text in the element changed to reflect the new, shared, understanding. Some participants asked the researcher to make the changes on the Wiggio whiteboard rather than do it themselves. One participant (as before in cycle 1) stated that he wanted the researcher to make changes to the map since he was not technologically proficient. We discovered that it was apparent that there were many issues that some of the RU participants didn't know (e.g. that there was a delay in getting the J1 visa for UK students) and many issues that were surprising to some participants from CC (e.g. that RU could only realistically market $\mathrm{CC}$ to $15 \%$ of their students). After discussing each of the elements in the systems map and agreeing on a group level interpretation, participants then moved on to an agreed version of the composite map.

The discussions during the second virtual session in cycle two revealed that the marketing issue was the most problematic challenge since there were several associated unknowns. They also realized that the success of the programme hinged largely on the success of their marketing both on campus and outside of it. As a result participants decided to discuss this element further and generate ideas on an initial marketing plan that would work for both institutions. Some issues arising from the discussion caused conflict especially when the $\mathrm{CC}$ cohort realized that their college would only be marketed to a limited percentage of RU students.

When participants initially argued on the conflictual issue the assertions seemed to be more existential or abstract in nature. The systems thinking tools PEArL and CATWOE 
(Checkland and Poulter 2006) were applied as a means of structuring the debate which focused the attention of participants on the specifics and forced them to discuss their motivations. The process made it more difficult to retain hidden agendas. Questions corresponding to each element in PEArL and CATWOE were used to encourage participants to reflect upon and discuss key issues relating to marketing. Using PEArL enabled participants to see the plethora of views on marketing and encourage a systemic, holistic appreciation of the situation. Additionally, PEArL encouraged participants to reflect upon issues that they typically ignored such as informal power (r) and its effect upon outcomes. Participants were also asked to reflect on the marketing component from the systems map by using the $\mathrm{T}$ and $\mathrm{W}$ from CATWOE to help them think about why they viewed the situation in a particular way (W) and the transformation (T) that they hoped to achieve by implementing an effective marketing plan. The purpose of the exercise was to expose participants to each other's world views and associated motivation with the intention of generating shared learning about the situation and reducing conflicts. The discussions encouraged participants to explain their reasoning in a more explicit way, which helped others understand the thinking behind their contributions. Participants from CC confirmed that the deeper investigation of the issues using PEArL and CATWOE enabled them to understand RU's future plans and that surfacing and discussing the issues helped diffuse the situation. Participants from RU acknowledged that the questions corresponding to the elements from PEArL and CATWOE helped them to organize their thoughts and explain their future plans in a more structured and comprehensible fashion. This situation suggests that CATWOE and PEArL had assisted in diffusing a potentially conflictual situation by creating an environment of shared learning (Table 4).

During the same virtual group session all participants were asked to think about the five PEArL elements in terms of "what is the case" concerning the marketing component, helping them to reflect on how the marketing of the program is currently actioned. PEArL was used here as a tool for reflection to enable the participants to discuss various aspects of the situation especially issues related to how participants in the situation currently engage with each other and how formal power and informal authority is exercised. Each element in PEArL was explained and the participants asked to talk about their perceptions about marketing in relation to each element. The answers given by participants are as follows (Table 5).

Table 4 Answers to CATWOE questions from participants on conflictual issue

\begin{tabular}{ll}
\hline CATWOE elements & Observations \\
\hline C-Customer & Students \\
A-Actors & $\begin{array}{c}\text { Director of Admissions in North America (Richmond) and Director of } \\
\text { Communications (Curry) }\end{array}$ \\
T-Transformation & $\begin{array}{c}\text { Students who don't know about the exchange program become aware } \\
\text { and excited about the program }\end{array}$ \\
O-Owner & Director of Admissions in North America (Richmond) and Director of \\
& Communications (Curry) \\
W-Worldview & Increasing revenue \\
E-Environment & English students are averse to studying abroad, most Richmond students \\
& are international students and they get an international experience just \\
by coming to Richmond so may not be interested in coming to the US, & J1 visa issues from the US end, problems with housing availability \\
\hline
\end{tabular}


Table 5 Answers to PEArL questions on how the conflictual issue is currently implemented (What is the case)

\begin{tabular}{ll}
$\begin{array}{l}\text { PEArL } \\
\text { elements }\end{array}$ & Observations \\
\hline Participants & $\begin{array}{c}\text { Currently registrar's office and Director of Admission's office, Director of } \\
\text { Communications }\end{array}$ \\
Engagement & $\begin{array}{c}\text { There is lots of confusion about who does what and who is in charge. Currently the } \\
\text { Marketing department is under the authority of the Director of Communications and } \\
\text { publishes brochures and limited web content to publicize the study abroad program. } \\
\text { There does not appear to be a holistic marketing policy yet }\end{array}$ \\
& $\begin{array}{l}\text { Director of Admissions in North America (Richmond) and Director of Communications } \\
\text { Authority }\end{array}$
\end{tabular}

Relationships The role of the marketing department is to oversee the way the college is marketed but there appeared to be some competition between one participant and the Marketing Department. The tension was demonstrated when the participant made several comments on how the marketing department did not know enough about the study abroad program to market it and that the marketing should be overseen by the people directly involved with getting the program implemented (aka 'the insiders'). This was in contrary to the usual scenario where the marketing department spearheads all the marketing campaigns for the college. The participant appeared to use their extensive knowledge of the study abroad program to bring the marketing of the study abroad program under the overview of a different department rather than the marketing department of the college. There were hints that the marketing department did not have adequate information to market the program effectively since they had not been involved in all the meetings previously. This influence may have led to the conclusion that a separate study abroad office had to be created which among other duties would lead the marketing efforts as well. The use of 'insider knowledge' and wider access to information by the said participant can be considered to be a 'commodity' of power used by him as an informal or 'soft' means of influencing others. This was not a formal use of power since all participants had a similar formal rank but some had participated in the meetings on the study abroad program (outside of this study) since the start while others had not

Lessons Some suspicions about who is in charge and about financial details being held back from certain key players

Participants were asked to think about the five elements of PEArL in terms of "what ought to be the case" concerning the marketing component. This helped them to reflect on how marketing of the program should ideally be actioned. The intention was to get participants to think 'outside the box' and identify what they would like to happen if they had unlimited resources and no constraints. The answers given by participants are as follows. Results of PEArL inquiry into how the selected element should be ideally implemented (what ought to be the case) (Table 6).

The reflection on "what is the case" and "what ought to be the case" was operationalized as a way of assisting participants to consider how things are done now with regards to the marketing aspect of the program and how things ought to be done. By reflecting on the issue using PEArL and CATWOE (in relation to marketing) participants were able to deconstruct or break down the discussion into aspects that provided better understanding of the reasoning behind decisions. This provided a more structured way for participants to deconstruct the conflictual issue and discuss elements pertaining to it.

Before the third virtual session in cycle two the researcher produced a definition of a system that could implement the selected element (marketing) which is similar to a root 
Table 6 Answers to PEArL questions on how the conflictual issue should be ideally implemented (What ought to be the case)

$\begin{array}{ll}\begin{array}{l}\text { PEArL } \\ \text { elements }\end{array} & \begin{array}{l}\text { Observations } \\ \text { Participants }\end{array} \\ \begin{array}{l}\text { Should have a separate study abroad office at Curry College that is the main point of } \\ \text { contact and does the coordination } \\ \text { Marketing Richmond to Curry students is easy since it sells itself. Marketing Curry to } \\ \text { Richmond students is hard to do due to the constraints discussed in E in CATWOE. Here } \\ \text { Curry needs to cherry pick certain programs that would be especially attractive to } \\ \text { Richmond students such as TV and radio in the COM department and market those } \\ \text { aggressively. Curry should especially be marketed to students taking the new American } \\ \text { studies major at Richmond. Use brochures, web references and social media }\end{array} \\ \begin{array}{l}\text { Head of study abroad office } \\ \text { Authority }\end{array} \\ \begin{array}{l}\text { Nelationships conflict that they could foresee } \\ \text { Lessons }\end{array} & \text { How to market the program effectively to targeted students }\end{array}$

definition in SSM. This definition was created using the answers that participants had given to the PEArL and CATWOE questions in the last session. The definition was to be used as a starting point for a discussion on what business processes would have to be ideally in place to effectively market the program. At the start of the session with the help of the researcher the participants evaluated and modified the definition. This activity corresponds to the way it would be undertaken in a face-to-face situation. After discussion on the words to use in the definition the following was agreed upon.

"A system owned by the Director of Communication and Study abroad office at RU and staffed by the study abroad office at CC and Study abroad office at RU to promote CC to RU students and promote RU to CC students by cherry picking and promoting programs that are especially attractive to students at the other institution and using social media, brochures and web references in order to provide students with international exposure to make them more employable and in order to make the institutions more attractive to potential new students in light of CC being marketed to only $13 \%$ of RU students, limited housing availability and the threat of long J1 visa delays."

The definition helped formalise the kind of 'system' participants thought would produce a good marketing plan, but they also needed to reflect on the processes that would be needed to implement the defined 'system'. Supported by the researcher the participants broke down the contents of the definition and used it as a guide to discuss the various activities that would help implement their vision. The activities they identified can be traced back to the definition and are as follows.

- Create a study abroad office at CC

- Create a marketing plan to promote $\mathrm{CC}$ to RU students

- Promote CC to RU students

- Create a marketing plan to promote RU to CC students

- Promote RU to CC students

- Identify current programs of study that are especially attractive to the student population at the other institution

- Promote selected programs to students of the other institution

- Train employees in the use of new media such as social media to promote programs 
- Determine the best way to use the study abroad program as a way of marketing the institutions to potential new students (not students from the other institution)

- Periodically assess the percentage of RU students, CC is being marketed to

- Monitor J1 visa wait times and changes

Once participants identified the processes that would help with the research question they realized that they needed the expertise of other departments in order to understand the processes better. They decided to take what they had learnt from the study so far and reach out to the marketing departments, faculty training centers and IT departments at their respective institutions to discuss the implementation of the processes.

The virtual sessions in cycle two bought the participants from both institutions together and helped them to use the combined systems map as a means of debating differing views. PEArL and CATWOE proved to be useful as way to structure debate when conflicts arise. The attention of participants was drawn to the separate elements in PEArL and CATWOE and they were forced to reflect on and justify their positions on the different elements in relation to the conflictual issue. When the issue was deconstructed in this manner participants were able to differentiate between what they would like and what was feasible. Although the conflictual issue was deconstructed we believe that the preceding discussions enabled participants to still see the "big picture" and the position of the conflictual element within it.

\section{Cycle Three}

The third cycle was organized 3 months after the previous session. During the intervening period participants encouraged those reporting to them to participate in the asynchronous discussion board set up on Blackboard to talk about the challenges associated with the study abroad program. A moderator was appointed to start discussion threads and converse with participants. Additionally steps were taken to increase faculty buy in by organizing informational events around campus at CC. A participant of the study also talked about the program at a monthly campus wide faculty meeting. Participants felt that their two pronged approach of sharing more information and creating avenues for conversations (with those directly involved and those uninvolved with the study abroad program) had created more awareness and positive interest among the employees of CC.

Participants also drew on the processes identified in the last session to have discussions with the marketing department, IT department and faculty center about marketing the study abroad program to students at RU. They suggested that the conversations during the previous cycles had provided them with more knowledge about the situation which enabled them to ask relevant questions from those in the other departments. Prior to the virtual session in the third cycle participants had worked with the other departments and decided that they were going to pursue a marketing strategy known as inbound marketing. For cycle three the web administrator of $\mathrm{CC}$ was asked to join by the participants.

During the synchronous virtual session participants discussed the inbound marketing strategy they had agreed upon for marketing CC to RU students. They listed the potential activities that should be implemented to do inbound marketing. These activities had been decided during the meetings held with other departments after the previous cycle.

- Create a blog for CC with posts from current students about student life

- Share information about the school, student life and Boston on social media

- Create a webpage dedicated to the study abroad program on the main CC website 
- Incorporate popular hashtags that RU students use on social media postings about the study abroad program at $\mathrm{CC}$

- Create ad campaigns on search engines to market the college to RU students

- Encourage the most influential social media users at RU to talk about the study abroad program at $\mathrm{CC}$

The researcher asked them to discuss and identify the information needed to implement said strategy and other processes identified in the last cycle. The initial draft of informational needs to market CC to RU students is as follows (Table 7). Participants were also

Table 7 Information requirements, sources and technologies identified by participants

\begin{tabular}{llc}
\hline Information requirement & Possible source & Need for technology \\
\hline $\begin{array}{l}\text { Information on good student bloggers } \\
\begin{array}{l}\text { Information on social media hashtags } \\
\text { popular among RU students }\end{array}\end{array}$ & $\begin{array}{c}\text { Faculty, CC social media manager } \\
\text { Social media manager; Institutional } \\
\text { research at CC }\end{array}$ & $\begin{array}{c}\text { No } \\
\text { Social media analytics } \\
\text { software } \\
\text { NodeXL is currently } \\
\text { available at CC }\end{array}$ \\
$\begin{array}{l}\text { Information on RU students most } \\
\begin{array}{l}\text { influential on social media } \\
\text { Social media managers at CC and }\end{array}\end{array}$ & $\begin{array}{c}\text { Social media analytics } \\
\text { software }\end{array}$ \\
$\begin{array}{l}\text { Information on search keywords most } \\
\text { popular among students searching for } \\
\text { study abroad programs on search } \\
\text { engines }\end{array}$ & Google adwords website & $\begin{array}{c}\text { NodeXL is currently } \\
\text { available at CC }\end{array}$ \\
\end{tabular}

Information on study abroad related search keywords most popular among students coming to the CC main website

Information on which CC courses can be substituted for requirements at RU

Information on which CC course options would be appropriate for an individual student at RU based on the requirements $\mathrm{s} /$ he has still to fulfil to graduate

Information on current methods of offline marketing at $\mathrm{CC}$

Information about programs of study that are especially attractive to the RU student population

Information on current J1 visa wait times and procedures

Information on popular behavior exhibited on CC website by RU students

Information on the experiences of RU students who come to $\mathrm{CC}$
Web analytics software, web logs

Registrar's office at CC, Registrar's office at RU, Academic department chairpersons at $\mathrm{CC}$

CC Registrar's office, Registrar's office at RU

CC marketing Department, brochures, catalogs, print advertisements

RU study abroad staff, RU faculty, RU career development office, surveys, RU graduation data

US citizenship and immigration services website, online discussion boards

RU IP address data, Web analytics software

Surveys, offline conversations with faculty and study abroad staff, student social media postings
Web Analytics software Google Analytics is currently available at $\mathrm{CC}$

Blackboard learning management system to share documents

Software to make CC course recommendations to RU students

No

No

Internet

Cookies, web analytics software

Survey software Qualtrics currently available at $\mathrm{CC}$ 
asked to identify potential sources from which to obtain the information and potential use of technology to obtain the information. The web administrator assisted in identifying potential technologies. An initial draft of the information requirements is as follows.

Participants agreed that the action plan and information requirements should be taken back to their organizations for further discussion with the $\mathrm{C}$ level staff and IT experts. Participants stated that what they learnt in the study would help them to have more informed conversations with those who did not take part. At that point the participants returned to their own organization to take the proposals forward.

A formal contract was signed by the institutions a few months later and "study abroad program" was launched: The first batch of US students were sent to the UK in the fall of 2014 while the first batch of UK students were sent to the US in Spring 2015. The study strengthens the argument that soft AR methods can help participants within a virtual setting to reach a shared understanding considering the resultant actions. The study also showed that AR could be useful in virtual synchronous IS development teams as a means of understanding the "system to be served" before considering technology. The study also demonstrated the usefulness of using these systems tools as a means to help diffuse conflicts by creating opportunities for more structured discussion, learning and the reaching of accommodations.

\section{Discussion}

Virtual AR subscribes to the same tenets as traditional AR that theory and practice can be closely integrated by learning from the results of interventions that are planned after a thorough diagnosis of the problem domain. In practice we found that conducting synchronous virtual AR is considerably different to traditional AR and make recommendations to help assure the quality of virtual AR practice, reporting and reviewing. We demonstrate the potential for virtual AR as an alternative method to be used in the analysis phase of ISD to help participants identify the information requirements of an IS. We also discuss the limitations of our study and ways in which to improve upon it in further research.

\section{AR in ISD}

When the CAO of CC commissioned the study he required an estimation of the technology needed to launch the study abroad program and the information requirements of users which correspond to the initial stages of the SDLC. The CAO realized that stakeholders of the research domain had limited understanding of different aspects of the situation. As such AR proved to be a suitable approach since it calls for participants to learn about all perspectives of the domain and identify the information requirements (system to be served) before considering the tools that will provide the information (serving system i.e. technology). Participants were able to expose and discuss multiple views of the situation leading to enhanced client learning. The client learning led to participants being able to identify business processes that could improve their domain. Participants were then able to debate on the information required to implement the identified business processes. Information requirements (see Table 7) were further analysed by participants and details about sources from where to procure the information, frequency in which information would be needed, format of information and training required by staff was discussed. Participants also began to debate on areas where technology could help with the gathering of required 
information and with the help of the web administrator were able to identify specific technologies (see Table 7). Participants also stated that they would be able to have more confident conversations with IT experts since they now had a better understanding of the domain, required processes and information requirements. Although the study concluded before conclusive technology choices were made we maintain that it demonstrates that AR would be useful in the requirements gathering, analysis and initial design stages of a virtual synchronous ISD project. When conducting virtual AR we recommend that virtual synchronous communication software (versus asynchronous software) be used in order to maximise the benefits of AR in ISD. We also suggest when selecting a communication tool that the facilitator considers one that has a shared drawing tool since we found that having a shared visual representation of ideas helped to ensure that the discussions were not rambling and prevented personal agendas from being hidden. Facilitators should also be aware of recent research on virtual teams about the increased difficulties in changing the original views of participants and making agreements harder to obtain in virtual teams. Several tools from AR were used in the study to address this issue of conflict.

\section{Conflict}

Recent research (Sarker and Valacich 2010) demonstrate that conflict is more prevalent in virtual teams since participants are more unwilling to change their preconceptions and biases when they never or rarely meet face to face. Although most of the discussions were devoid of conflict, there were several conflictual situations in cycles one and two. We found that initially participants were discussing the conflictual issues in an existential or high level context rarely explaining the frame of mind or motivations for their assertions which led to more accusations and tension. In order to reduce tension and focus the discussion around the specifics the researcher used the strategy of exploring the problem issue in the context of the elements from PEArL (Stowell and Welch 2012) and CATWOE (Checkland 1981). The tools allowed participants to draw attentions away from how they felt emotionally and identify underlying personal motivations for their views of the issue of conflict. They then used the elements in PEArL and CATWOE to structure their assertions and present their reasoning in a more organized fashion. Participants from RU stated that the questions corresponding to the elements from PEArL and CATWOE helped them to organize their thoughts and explain their future plans in a more structured and comprehensible fashion. All participants agreed that the process helped them to reduce tensions and arrive at an agreement. This provides some level of support to the use of AR (e.g. AIM, PEArL and CATWOE) as a way of creating shared understanding leading to reduced conflicts in virtual teams. If AR is to be a mainstream choice in virtual ISD we argue that facilitators should decide on tactics participants could use for self-reflection and deconstruction of an issue of conflict before the project begins.

\section{Rigour}

In order to maintain rigor and authenticity in the study we drew on work on the recoverability of AR (Checkland and Poulter 2006); authenticity of AR (Champion and Stowell 2001) and criteria for rigor in AR (Iversen et al. 2004). These steps provide a third party with the opportunity to recover the process and the logical pathway leading to the conclusions. We used the FMA model (Checkland and Poulter 2006) to 'set out the stall' before the study began in order to ensure the recoverability (Checkland 1981) of the research. We also took care to record details of the study pertaining to the six criteria that 
Iverson et al. (2004) argues leads to relevance and rigor in AR. PEArL records (Champion and Stowell 2001; Cooray 2010; Hart 2013) were produced after each session (Table 2) detailing the manner and atmosphere of each session. This was done to help external parties to interpret the results in the context in which the study took place.

We found that the communication software used (Wiggio) hindered the authentication of the study. Traditionally when authenticating an AR study the facilitator is expected to observe and record any use of power during the session (r) and the way in which participants engaged with each other (E). Although Wiggio allowed each participant to see and converse via the video feed to all other participants, visually they were confined to small windows in the software. We found that it was difficult for the researcher to monitor the many mini screens simultaneously leading to the possibility that many gestures and facial cues could be missed. This leads us to question if the facilitator could truly observe and record the manner or atmosphere within which the synchronous virtual discussions were held which in turn compromises the authentication process of the study. The authentication process could be more difficult in asynchronous virtual communication since participants can add their contributions at different times limiting the facilitator's ability to observe the manner/atmosphere and group dynamics.

\section{AIM and AR}

The goal of enabling client learning in AR relies on the ability of clients to participate fully in the discussions. Subsequently the tools used for discussion should be simple and easy to use. We found that in the virtual AIM sessions the systems map was a suitable agenda for discussion since it was easy to understand and edit. Those who claimed to be more technically experienced easily added, edited and deleted elements from the systems map. Those participants who professed to be less technically able were reluctant to edit the map using the software tool. These participants frequently asked for help to complete the task rather than edit the map themselves. When such a situation arose we asked for immediate feedback to ensure that participant views were reflected in the resultant map. Since the meetings were held synchronously participants were able to provide instant feedback and make changes if the map didn't reflect their views. Methods such as AIM that promote more client participation are important in ISD teams to ensure that clients are given the chance to learn about all aspects of the situation before deciding on the information requirements of an IS.

\section{Power}

At the end of the study all participants agreed that they were able to fully participate in the study. However, we found that the less technically able participants publicly announced their lack of confidence and attempted to pass control of the sessions to others in the group. This overt behaviour might mean that the more technically knowledgeable participants could exercise more influence over the direction in which the discussions progressed. We observed, that in this exercise the more technically proficient participants did seem to use their expertise as a way of influencing others. This was exacerbated because the less technically able were hesitant creating the impression that they were happy to leave this aspect to others. (N.B. It could also be an example of the use of soft power; the implication being a form of ready-made excuse if things went wrong). In order to mitigate this issue we used PEArL to record the informal power relations that were observed. These records enable a third party to consider the results within the atmosphere and context in which the 
study took place. We recommend that in future AR studies that researchers be vigilant about both formal and informal power relations among participants and record them using authenticating tools such as PEArL. This process would help ensure the authenticity (Champion and Stowell 2001) of the AR inquiry.

\section{Cycle of Learning}

In each of the three cycles of the study we followed the diagnosing- action planning- action taking and evaluating cycle of AR prescribed by Susman and Evered (1978). We found that in all three phases participants changed their perceptions about the way that they viewed the partnership between the two institutions. Several of the participants realized that they had not previously understood the whole picture as their views were exposed to others and more aspects of the situation came to light. This was demonstrated when participants engaged in debate and iteratively modified the models they produced in each phase; some participants even changed their own bubbles in the systems maps following the discussions. While the study generated initial insight on the value and limitations of AR within a synchronous virtual team, it is difficult to generalize the findings or ascertain the applicability to contexts different from the one in which it was conducted. Multiple iterations of the AR cycle should be conducted in different con2002texts to strengthen the findings of this research and address the threat of contingency (Kock 2002; Ketchum and Trist 1992) which Action researchers in general face.

\section{Subjectivity of Researcher}

Literature shows that action researchers find it difficult to avoid consciously or subconsciously influencing the situation (Galliers 1993; Gioia 1992). Researchers (Kock 2002) have suggested solutions such as grounded theory and multiple iterations. Here we addressed the issue by creating PEArL records at the end of each session to reflect on and detail the way in which the researcher participated in the session. Each record discussed the people the researcher engaged with $(\mathrm{P})$, how she engaged with participants $(\mathrm{E})$, who had the formal authority in each session (A), if the researcher was the initiator or recipient of informal authority (r), and what the researcher learnt about the way she engaged in each session (L). The process of reflection after each session helped the researcher to identify the ways in which she influenced the situation and take measures to address them. The records on the researcher's interactions could also assist external parties to interpret results in the context of the situation. We suggest such methods of reflection on the researcher's interactions are especially important in virtual IS teams for IT experts to reflect on their facilitation and ensure that client perspectives are given priority. Such records can also be used by IT experts to demonstrate that their influence was kept to a minimum.

\section{Conclusion}

Modern organizations exist in an environment that is constantly changing thanks to developments in technologies, globalization and outsourcing among others. These continued trends have led to more geographically dispersed organisational teams that rarely, if ever, meet. This is especially true in the area of IS development that is frequently conducted by virtual teams. If $\mathrm{AR}$ is to be a more mainstream approach in virtual teams (e.g. 
ISD teams, global executive teams) then it is prudent that guidelines on how to conduct, report and review projects be provided. In this paper we address this need by demonstrating how participants in a virtual synchronous team were able to go through several cycles of action and reflection to arrive at a better understanding of the problem domain, information requirements and technology needs. We provide recommendations on issues that virtual action researchers should be aware of and demonstrate how AR (e.g. the Lancaster model of AR-soft AR) can be useful as a means of overcoming conflicts more prevalent in virtual teams. We hope that more researchers will be encouraged to engage in virtual AR and explore the myriad of issues associated with it.

Open Access This article is distributed under the terms of the Creative Commons Attribution 4.0 International License (http://creativecommons.org/licenses/by/4.0/), which permits unrestricted use, distribution, and reproduction in any medium, provided you give appropriate credit to the original author(s) and the source, provide a link to the Creative Commons license, and indicate if changes were made.

\section{References}

Alter S (2013) "Work System Theory: Overview of Core Concepts, Extensions, and Challenges for the Future". Business Analytics and Information Systems. Paper 35

Argyris C, Schön D (1996) Organizational learning II: theory, method and practice. Addison Wesley, Reading

Argyris C, Putnam R, Smith D (1985) Action science: concepts, methods and skills for research and intervention. Jossey-Bass, San Francisco

Ashrafi N, Ashrafi H (2008) Object oriented systems analysis and design. Prentice Hall, New York

Avison DE, Wood-Harper AT (1990) Multiview: an exploration in information systems development. McGraw-Hill, New York

Baskerville R (1999) Investigating information systems with action research. Commun Assoc IS 11(3):235-246

Baskerville R, Wood-Harper AT (1996) A critical perspective on action research as a method for information systems research. J Inf Technol 11(3):235-246

Blum F (1955) Action research—a scientific approach? Philos Sci 22(1):1-7

Champion D, Stowell FA (2001) PEArL: a systems approach to demonstrating authenticity in information system design. J Inf Technol 16(1):3-12

Champion D, Stowell FA (2005) Client led information systems creation-navigating the gap. Inf Syst J 15(3):213-231

Checkland P (1981 \& 1990) Systems thinking systems practice. John Wiley, Chichester

Checkland PB (1999) Systems thinking, systems practice, includes 30 year retrospective. Wiley and Sons, Chichester

Checkland PB, Holwell S (1998) Information, systems and information systems. Wiley, Chichester

Checkland PB, Poulter J (2006) Learning for action. Wiley, Chichester

Checkland PB, Scholes J (1999) Soft systems methodology in action: 30 year retrospective. Wiley and Sons, Chichester

Chiasson M, Germonprez M, Mathiassen L (2009) Pluralist action research: a review of the information systems literature. Inf Syst J 19(1):31-54

Churchman CW (1971) The design of inquiring systems: basic concepts of systems and organisation. Basic Books, New York

Cooray S (2010) End user driven development of information systems: revisiting Vickers notion of appreciation. PhD Thesis, University of Portsmouth, Portsmouth

Corbett M (2004). The orusourcing revolution, (WWW document) https://www.economist.com/media/ globalexecutive/outsourcing_revolution_e_02.pdf. Accessed 10 Feb 2016

Davidson E (2002) Technology frames and framing: a socio cognitive investigation of requirements determination. MIS Q 26(4):329-358

Deloitte (2014) Global outsourcing and insourcing survey, (WWW document) https://www2.deloitte.com/ content/dam/Deloitte/us/Documents/strategy/us-2014-global-outsourcing-insourcing-survey-report123114.pdf. Accessed 1 Feb 2016

Emery F, Thorsrud E (1976) Democracy at work. Nijhoff, Leiden 
Friedman V, Rogers T (2013) Action Science: Linking causal theory and meaning making in action research. In: Rason P, Bradbury H (eds) Handbook of action research. Sage, London, pp 252-265

Gadamer HG (1998) Truth and method, 2nd edn. Continuum, New York

Galliers RD (1993) Research issues in information systems. J Inform Technol 8(2):92-98

Gioia DA (1992) Pinto fires and personal ethics: a script analysis of missed opportunities. J Bus Ethics 11:379-389

Gonzales A, Dorwin D, Gupta D, Kalyan K, Schimler S (2004) Outsourcing: past, present and future. (Unpublished paper)

Greenwood D, Levin M (2006) Introduction to action research: social research for social change. Sage, Newbusry Park

Gustavsen B (1983). Sociology of action: on the constitution of alternative realities. Unpublished paper, Work Research Institute, Oslo

Habermas J (1972) Knowledge and human interests. Trans. Jeremy J. Shapiro. London, Heineman

Hart PJ (2013) Investigating Issues Influencing Knowledge Sharing in a Research Organization Using AIM. Unpublished doctoral dissertation, University of Portsmouth, England

Husserl E (2002) Pure phenomenology: its method and its field Of investigation. In: Moran D, Mooney T (eds) The phenomenology reader. Routledge, London, pp 124-133

Ison R (2013) Systems thinking and practice for action research. In: Rason P, Bradbury H (eds) Handbook of action research. Sage, London, pp 139-159

Iversen J, Mathiassen L, Nielsen PA (2004) Managing risk in software process improvement: an action research approach. MIS Q 28(3):395-433

Kanawattanachai P, Yoo Y (2007) The impact of knowledge coordination on virtual team performance over time. MIS Q 31(4):783-808

Kermmis S (2013) Critical theory and participatory action research. In: Rason P, Bradbury H (eds) Handbook of action research. Sage, London, pp 121-139

Ketchum L, Trist E (1992) All teams are not created equal: how employee empowerment really works. Sage Publications, Newbury Park, CA

Kock N (2002) Action research. In: Segaard R, Dam RF (eds) The encyclopedia of human-computer interaction. Interaction design foundation, Open Source, Open Access Literature

Lewin K (1948) Action research and minority problems, resolving social conflicts. Harper Row, New York

Lindgren R, Henfridsson O, Schultze U (2004) Design principles for competence management systems: a synthesis of an action research study. MIS Q 28(3):435-472

Mårtensson P, Lee AS (2004) Dialogical action research at Omega Corporation. MIS Q 28(3):507-536

Mathiassen L, Munk-Madsen A, Nielsen PA, Stage J (1991) Soft Systems in Software Design. In: Jackson MC et al (eds) Systems thinking in Europe. Plenum Press, New York, pp 311-317

Mingers J, Brocklesby J (1997) Multimethodology: towards a framework for mixing methodologies. Omega 25:489-509

Montoya-Weiss M, Massey A, Song M (2001) Getting it together: temporal coordination and conflict management in global virtual teams. Acad Manag J 44(6):1251-1262

Mumford E, Weir M (1979) Computer systems in work design-the ETHICS method. Associated Business Press, London

Paetsch F, Eberlein A, Maurer F (2003) Requirements engineering and agile software development: In: 12th IEEE International Workshops on Enabling Technologies: Infrastructure for Collaborative Enterprises (Linz, Austria), IEEE press, pp. 308-314

Paulus T, Phipps G (2008) Approaches to case analyses in synchronous and asynchronous environments. J Comput Mediat Commun 13(2):459-484

Pena-Shaef J, Martin W, Gray G (2001) An epistemological framework for analyzing student interactions in computer-mediated communication environments. J Interact Learn Res 12(1):41-68

Pui See, Ng C, Gable G (2010) Maintaining packaged software: a revelatory study. J Inf Technol 25(1):65-90

Reason P, Bradbury H (eds) (2013) Sage handbook of action research: participative inquiry and practice, 2nd edn. Sage Publications, London

Reason P, Rowan J (eds) (1981) Human inquiry: a sourcebook of new paradigm research. Wiley, Chichester

Sarker S, Valacich J (2010) An alternative to methodological individualism: a non-reductionist approach to studying technology adoption by group. MIS Q 34(4):779-808

Sassenberg K, Boos M, Rabung S (2005) Attitude change in face-to-face and computer-mediated communication: private self-awareness as mediator and moderator. Eur J Soc Psychol 35:361-374

Schutz A (1970) In: Wagner H (ed) On phenomenology and social relations: selected writings. University of Chicago Press, Chicago 
Stowell FA (1989) Change, organizational power and the metaphor 'commodity. Unpublished doctoral dissertation, University of Lancaster, England

Stowell FA (2014) Organisational power and the metaphor commodity. Int J Sys Soc 1(1):12-20

Stowell FA, Welch C (2012) The managers guide to systems practice, making sense of complex problems. Wiley, Chichester

Susman G, Evered R (1978) An assessment of the merits of scientific action research. Admin Sci Q 23(December):583-603

Torbert WR (2001) The practice of action inquiry. In: Reason P, Bradbury H (eds) The handbook of action research: participative inquiry and practice. Sage Publications, London, pp 250-260

Trist E, Bamforth K (1951) Some social and psychological consequences of the longwall method of coal getting. Human Relat 4:3-38

Vickers G (1983) The art of judgement. Harper Rowe, London

West D (1995) The appreciative inquiry method: a systemic approach to information systems requirements analysis. In: Stowell FA (ed) Information systems provision: the contribution of soft systems methodology. McGraw-Hill, Maidenhead, pp 140-158

Zmud R (1998) Editor's comments, MIS Q 22(2):xxxix-xxxii 